\title{
An Analytical Method of Coulomb's Active Earth Pressure Acting on Cohesion-Less Backfill Subject to Local Surcharge in Cold Regions
}

\author{
Li Liu, ${ }^{1}$ Zhen Yang, ${ }^{2}$ Pan Zhou, ${ }^{3}$ and Hongwei Yang $\mathbb{D}^{4}$ \\ ${ }^{1}$ Department of Construction Engineering, Shanxi Polytechnic College, Taiyuan, Shanxi 030006, China \\ ${ }^{2}$ School of Mechanics and Civil Engineering, China University of Mining and Technology, Xuzhou, Jiangsu 221116, China \\ ${ }^{3}$ Department of Geotechnical Engineering, Tongji University, Shanghai 200092, China \\ ${ }^{4}$ College of Architecture and Civil Engineering, Xi'an University of Science and Technology, Xi'an, Shaanxi 710054, China
}

Correspondence should be addressed to Hongwei Yang; yanghw.xust@foxmail.com

Received 17 June 2020; Revised 6 July 2020; Accepted 18 August 2020; Published 29 August 2020

Academic Editor: Ping Cao

Copyright (C) $2020 \mathrm{Li} \mathrm{Liu}$ et al. This is an open access article distributed under the Creative Commons Attribution License, which permits unrestricted use, distribution, and reproduction in any medium, provided the original work is properly cited.

\begin{abstract}
The traditional Coulomb's earth pressure theory does not consider the effect of local surcharge on the lateral earth pressure and its critical failure angle. However, in practice, local surcharges commonly act on the surface of frozen backfill that is affected by freeze-thaw actions in cold regions and tend to affect the active thrust and its position. In paper, analytical solutions for estimating the active thrust, critical wedge failure angle, and action position subject to a local surcharge in cold regions are proposed. Herein, the simplified equivalent moment of surcharge is adopted on the premise of maintaining Coulomb's earth pressure assumptions. The formula derivation is provided as a typical example to obtain the active thrust, critical wedge failure angle, and its position under a strip surcharge. Compared with previous approaches, the proposed solutions lead to easier evaluation of all indexes associated with Coulomb's active earth pressure. Meanwhile, the expressions of Coulomb's earth pressure under other types of nonuniform loading acting on the wall are discussed. In addition, sensitivity is performed to assess the effect of some main parameters. The results indicate that the dip angle of retaining wall-back and the friction angle of frozen backfill soil are two most significant indexes that influence the active thrust and its position.
\end{abstract}

\section{Introduction}

Coulomb's earth pressure theory, proposed in 1776, assumes a planar failure surface developed within cohesion-less backfill [1]. Namely, the possible failure shape is regarded as a geometric invariable wedge. The earth pressure against the retaining wall can then be handily analyzed and approximated. In geotechnical engineering, Coulomb's earth pressure theory has been widely used to estimate the earth pressure against retaining structures [2-7].

The classical Coulomb's earth pressure theory considers the influence of self-weight of backfill on the earth pressure acting on the retaining structures. Practically, however, surcharges (in form of static loading, dynamic loading, and cyclic loading) are commonly present on the surface of backfill and tend to influence the earth pressure [8-12]. Besides, due to the effect of surcharge, the corresponding reinforcement treatment also has a great influence on the lateral distribution of earth pressure [13]. Therefore, it is necessary to extend classical Coulomb's earth pressure theory by considering the influence of various surcharges. Some studies have been carried out for this purpose. For instance, some researchers improved Coulomb's earth pressure models under the global surcharge condition based on the theoretical method [14-19], and a few attempted to improve Coulomb's earth pressure model for the global surcharge using experimental tests $[20,21]$. Numerical methods $[22,23]$ have also been used to modify the traditional Coulomb's earth pressure model with a uniformly distributed surcharge. 
In practice, the surcharges acting on the top surface of backfill also include nonuniform local surcharges, such as concentrated loading, strip loading, double concentrated loading, and triangular loading. The earth pressures under these conditions may be overestimated using previous methods based on uniformly distributed loading. However, the earth pressure analyses in presence of the local loading have rarely been studied. Ke et al. and Faraneh investigated the active earth pressure's variation regularity aiming at different distribution patterns of strip loadings in virtue of the closed vector polygon of force method [24, 25]. Zhao, Georgiads, and Anagnostopoulos et al. carried out a series of hydraulic loading tests to analyze the active earth pressure's variation regularity by adjusting the patterns of strip loading value and its force position [26, 27]. Despite these research outcomes, some significant defects still exist. Firstly, the derived formulas are too complex to apply in practice directly. It is difficult to achieve the accurate evaluation results of active earth pressure. Secondly, the consideration behavior of surcharge loading forms seems to be relatively single. In the previous works, the strip loading was just discussed to establish the evolution system. Some special nonuniformly distributed loading such as double strip loading, triangular loading, double triangular loading have been rarely studied.

In cold regions engineering, the backfill is always in a negative temperature state and forms frozen backfill with shorter thawed period and longer frozen period [28]. The frozen backfill in permafrost is different from common backfill because it is composed of solid particles, plastic ice crystals, unfrozen water, and gaseous components [29-31]. Therefore, You and Guo et al. found that the mechanical properties of frozen backfill are susceptible to the soil temperature and moisture based on permafrost engineering monitoring in the Qinghai-Tibet Plateau [32, 33]. Zhang, Teng, and $\mathrm{Xu}$ et al. conducted a series of tests to study the relationship between mechanical parameters of frozen soil and temperature and established the strength criterion for frozen soil, which is different from the traditional strength criterion [34-37]. Thus, it is necessary for studying the behavior of frozen backfill subject to local surcharge to consider the influence of ambient temperature.

In this study, the aim is to develop a systematic analytical solution for estimating active thrust, critical wedge failure angle, and action position under different local surcharges acting on frozen backfill in cold regions. By adopting the basic assumptions of Coulomb's earth pressure theory, a simplified method considering equivalent moment of surcharge is proposed to represent different types of local surcharges located on any position of the frozen backfill top. The detailed derivation procedures are also provided as a typical example to obtain the active thrust, critical wedge failure angle, and its action position subject to a strip surcharge. Furthermore, some other expressions of Coulomb's earth pressure suffering from most of other nonuniformly distributed loading acting on frozen backfill are proposed. The sensitivities of some main parameters involving Coulomb's earth pressure theory to the earth pressure for the local surcharge are also discussed.

\section{Proposed Analytical Model for the Cohesion- Less Backfill Subject to Local Surcharge}

2.1. Assumption of Failure Surface. When the wall friction $\delta \neq 0$, the failure surface commonly tends to a complex surface related to the wall displacement mode [38]. However, the model established in this work aims to analyze the effect of local loading on active earth pressure within the statics condition strictly, which can be regarded as an extension Coulomb's earth pressure model. Additionally, the shape of failure surface can be considered as a plane in cohesion-less backfill on the basis of basic assumption of the traditional Coulomb's earth pressure theory [39, 40]. Therefore, in order to catch the core question about the effect of local surcharge on the earth pressure for frozen backfill, the failure surface is assumed as a plane condition and the failure wedge shape also is regarded as a geometric invariable body, which means that its shape will not change regardless of any surcharge loading conditions. The similar treatments are also adopted by some former literature [24, 41-43].

2.2. Stability Analysis with Possible Failure Wedge. The basic Coulomb's earth pressure models subject to strip loadings are shown in Figures 1 and 2. A strip loading is located on the right of the gravity center of frozen backfill on Figure 1 and on the left of the gravity center of frozen backfill on Figure 2. The models are described as follows: (1) a gravity retaining wall with an inclined back face (incline angle $\alpha$ ); (2) a cohesion-less soil (for instance, sandy soil) is backfilled behind the wall; (3) the frozen backfill surface has a constant inclination angle $\beta$ to the horizontal direction; and (4) the possible failure wedge maintains a geometric invariable body and the failure slip angle can be regarded as a constant $\theta$.

The related forces are involved in this model as follows:

(1) The total weight of cohesive-less soil wedge $G$ : the weight $G$ can be obtained easily according to its frozen backfill soil density and its corresponding wedge volume.

(2) The intensity of local strip loading $q$ acting on one place of frozen backfill surface: the accurate value $q$ should be definite according to the requirement of our model.

(3) The resultant back force $E$ of retaining wall with the inclination angle $\delta$ relative to normal direction to the back face: herein, the back force position $C^{\prime}$ should be unknown.

(4) The resultant counter force $R$ acting on the probable failure surface with the inclination angle $\varphi$ relative to normal direction to the failure slip face: the inclination angle $\varphi$ of resultant counter force is equal to internal friction angle of frozen backfill soil which is effected by soil temperature $[32,33,44]$. Thus, the $\phi$ can be defined as $\Phi(T)$. Likewise, the slip counter position $D^{\prime}$ is also unknown.

Therefore, it is clear that there exist four unknown parameters: $E, R$ and their action sites $C^{\prime}, D^{\prime}$. However, only 


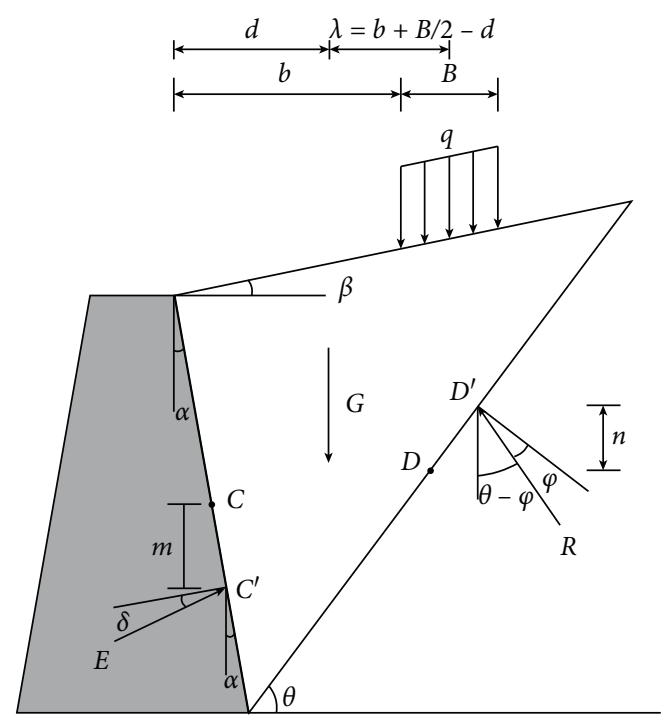

(a)

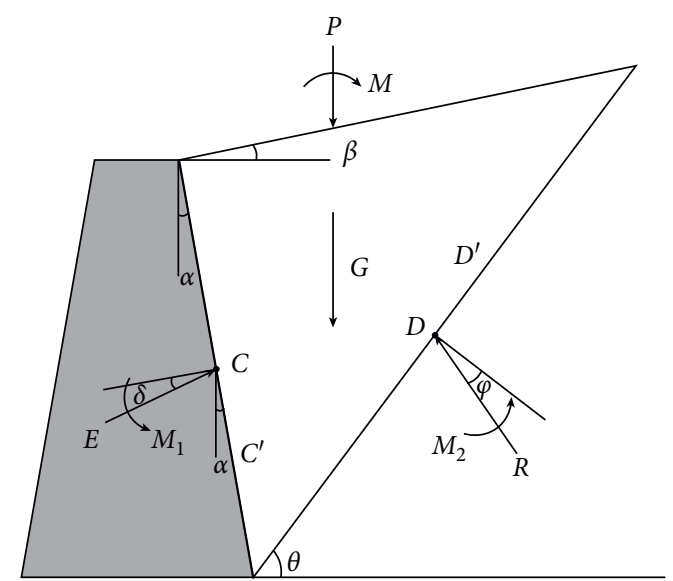

(b)

Figure 1: The midpoint of strip loading is on the right of the backfill gravity center. (a) Physical model. (b) Equivalent moment model.

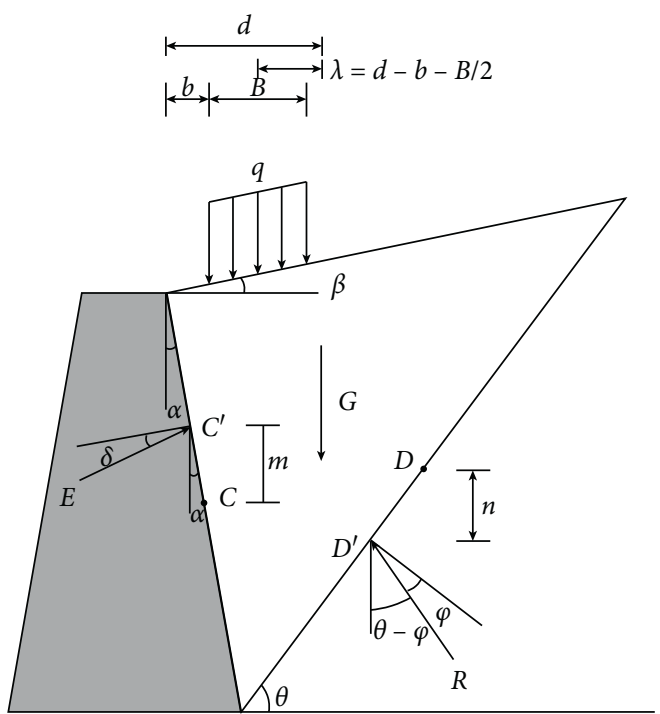

(a)

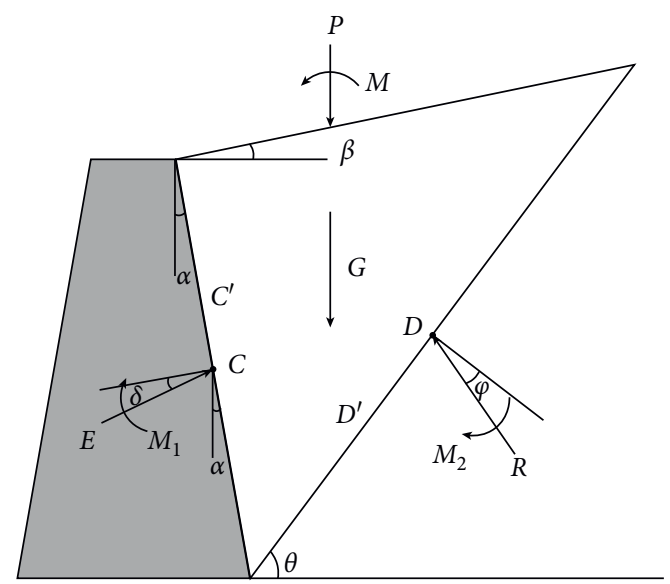

(b)

Figure 2: The midpoint of strip loading is on the left of the backfill gravity center. (a) Physical model. (b) Equivalent moment model.

three equilibrium equations can be established according to the forces equilibrium condition of failure wedge. Accordingly, it is necessary to obtain a correlation formula with two unknown variables in order to realize the analytical solution.

Supposing there is no exterior local loading acting on the surface of frozen backfill and only self-weight of probable failure wedge is considered, the resultant force $E^{\prime}$ should be acted at the centroid situation $C$ (namely, $H / 3$ ). And we also suppose the action position of failure surface resultant force $R^{\prime}$ located in some one situation $D$. In comparison, if there exists a local strip loading acting on the surface of frozen backfill, the correlations among the abovementioned forces can be divided into the following three cases:
(1) If the equivalent action position of local loading just locates on the action line of gravity, the original $E^{\prime}$ and $R^{\prime}$ should increase to the new $E$ and $R$, respectively. However, both their action positions remain unchanged.

(2) If the equivalent action position of local loading distributes on the right of the action line of gravity center (seen in Figure 1(a)), according to the transfer effect of force in granular soil $[45,46]$, the action position of $R$ will move upward from the original $D$ to $D^{\prime}$, while the action position of $E$ will move downward from the original $C$ to $C^{\prime}$. In order to build a unified analysis model, we use an equivalent 
moment to treatment to the surcharge condition as follows: firstly, we move the equivalent concentrated loading $P$ (if the local load is a strip load, the concentrated loading can be expressed as $P=B q$ ) to the action line of gravity and add an equivalent additional moment $M$. Then, we move the resultant force $E$ back from the original $C$ ' to the new site $C$ and add an equivalent additional moment $M_{1}$, and also we move back the failure surface resultant force $R$ from its original site $D \prime$ to the new $D$ and provide an equivalent additional moment $M_{2}$. The new equivalent moment model of surcharge located on the right of gravity center can be seen in Figure 1(b).

(3) If the equivalent action position of local loading distributes on the left of the action line of gravity center (Figure 2(a)), similarly, the reverse equivalent additional moments $M, M_{1}$, and $M_{2}$ can be also obtained. Meanwhile, the equivalent moment model of this kind of surcharge can be demonstrated as in Figure 2(b).

Accordingly, a new physical model including the equivalent concentrated loading and its corresponding equivalent additional moment can be established. In this model, the concentrated loading $P$ only affects the value changes of the parameters $E$ and $R$, and the equivalent additional moment $M$ controls the action positions $C /$ and $D$ I. Herein, in order to study the correlation formula with some two abovementioned unknown variables, we present a new variable $\mu=n / m$ (it presents the ratio between the vertical distance $n$ from sites $C$, to $C$ and the vertical distance $m$ from sites $D$, to $D$ ). It should be impacted by physical and mechanism parameters of the frozen backfill soil and the back face soil interaction. Supposing the value of $\mu$ is known, it will tend to be easy to establish the three equilibrium equations with three unknown variables: $E, R$, and $\mu$. Hereby, the accuracy and variability of this model will be only affected by the new variable $\mu$.

\section{Formula Derivation Processes considering the Influence of Freezing-Thawing Process}

3.1. Geometric Parameters of Possible Failure Wedge. The physical model of possible failure wedge is illustrated in Figure 3, and the length of probable failure surface is expressed by $J$. The distance from the midpoint of probable failure surface to the vertex of back face of retaining wall is presented as $e$, while the length of upper face of probable failure wedge is $L$.

According to the sines law, the following correlations can be obtained:

$$
\frac{J}{\sin ((\pi / 2)+\beta-\alpha)}=\frac{(H / \cos a)}{\sin (\theta-\beta)}=\frac{L}{\sin ((\pi / 2)+\alpha-\theta)} .
$$

Furthermore,

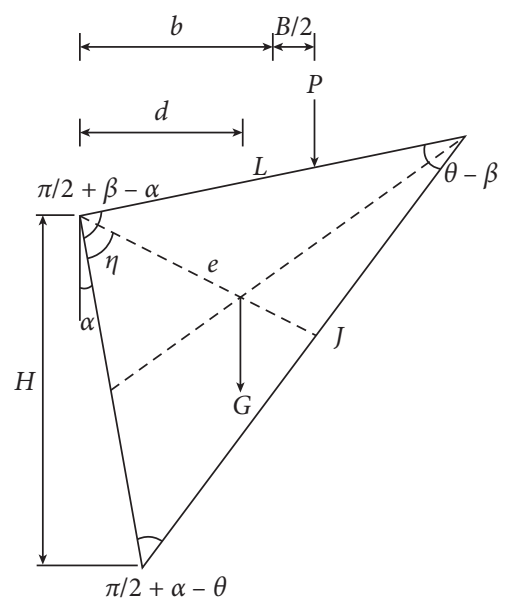

FIGURE 3: Correlations of the geometric parameters of the probable failure wedge.

$$
\begin{aligned}
& J=\frac{H \cdot \cos (\beta-\alpha)}{\cos \alpha \cdot \sin (\theta-\beta)}, \\
& L=\frac{H \cdot \cos (\alpha-\theta)}{\cos \alpha \cdot \sin (\theta-\beta)} .
\end{aligned}
$$

Then, the area $S$ of the probable failure wedge can be expressed as the following form:

$$
\begin{aligned}
S & =\left(\frac{1}{2}\right) \cdot\left(\frac{H}{\cos \alpha}\right) \cdot L \cdot \sin \left(\left(\frac{\pi}{2}\right)+\beta-\alpha\right) \\
& =\frac{H^{2} \cos (\alpha-\theta) \cdot(\beta-\alpha)}{2 \cos ^{2} a \cdot \sin (\theta-\beta)} .
\end{aligned}
$$

Hence, the gravity of frozen backfill can be presented as

$$
G=\gamma S=\frac{\gamma H^{2} \cos (\alpha-\theta) \cdot \cos (\beta-\alpha)}{2 \cos ^{2} \alpha \cdot \sin (\theta-\beta)} .
$$

The horizontal distance $d$ from the gravity center of probable failure wedge to the vertex of back face of wall can be achieved as

$$
d=\sin (\eta+\alpha) \cdot\left(\frac{2}{3}\right) e=\left(\frac{2}{3}\right) e(\sin \eta \cdot \cos \alpha+\cos \eta \cdot \sin a) .
$$

These two formulas can be obtained according to the trigonometric law where $\sin \eta=(J \cos (\alpha-\theta) / 2 e)$ and $\cos \eta=((2 H / \cos \alpha-J \sin (\theta-a)) / 2 e)$, we substitute them into formula (5), and the horizontal distance $d$ can be obtained:

$$
d=\left(\frac{2}{3}\right) H \tan \alpha+\frac{H \cos \theta \cdot \cos (\beta-\alpha)}{3 \cos \alpha \cdot \sin (\theta-\beta)} \text {. }
$$

3.2. Active Earth Pressure. According to the static equilibrium of probable failure wedge, 


$$
\begin{aligned}
& \sum F_{x}=0, \quad E \cos (\alpha+\delta)-R \sin [\theta-\Phi(T)]=0, \\
& \sum F_{y}=0, \quad B q-E \sin (\alpha+\delta)-R \cos [\theta-\Phi(T)]+G=0 .
\end{aligned}
$$

And referring to (4), (7), and (8), the resultant force $E$ and the failure surface resultant force $R$ can be obtained as

$$
\begin{aligned}
& R=\frac{2 B q \cdot \cos ^{2} \alpha \cdot \sin (\theta-\beta)+\gamma H^{2} \cos (\beta-\alpha) \cdot \cos (\alpha-\theta)}{2 \cos ^{2} \alpha \cdot \cos [\theta-\Phi(T)] \cdot \sin (\theta-\beta)+2 \cos ^{2} \alpha \cdot \tan (\alpha+\delta) \cdot \sin [\theta-\Phi(T)] \cdot \sin (\theta-\beta)}, \\
& E=\frac{2 B q \cdot \cos ^{2} \alpha \cdot \sin (\theta-\beta)+\gamma H^{2} \cos (\beta-\alpha) \cdot \cos (\alpha-\theta)}{2 \cos ^{2} \alpha \cdot \sin (\alpha+\delta) \cdot \sin (\theta-\beta)+2 \cos ^{2} \alpha \cdot \cos (\alpha+\delta) \cdot \cot [\theta-\Phi(T)] \cdot \sin (\theta-\beta)}
\end{aligned}
$$

It is easy to be observed that these values of $B, q, \alpha, \beta, \delta, \gamma$, and $H$ are the constants, the $\Phi(T)$ is a relative constant when the soil temperature is fixed, and only the $\theta$ is a variable parameter. In order to determine the maximum value (namely, the active thrust $E_{a}$ ) under the critical value condition (the critical wedge failure angle $\theta_{\text {cr }}$ ), the functional derivation can be used as

$$
\left(\frac{\mathrm{d} E}{\mathrm{~d} \theta}\right)=0 .
$$

The solving processes of all the preceding equations used the iterative method which works in the mathematical calculation software Matlab 7.0 [47]. In special case, if we substitute the critical value $\theta_{\text {cr }}$ into (10), the ultimate failure wedge can be fixed. And the corresponding active earth pressure $E_{a}$ under strip loading can be obtained.

It also should be noted that (10) can be restored to the original Coulomb's active earth pressure formula if the surcharge disappears which is $P=0(B=0$ or $q=0)$.

3.3. Action Position of Active Force. According to the moment equilibrium of failure wedge,

$$
\sum M=0 \lambda B q=\left(\frac{\cos \delta}{\cos \alpha}\right) m E+\frac{\cos [\Phi(T)]}{\sin \theta_{\mathrm{cr}}} n R,
$$

wherein the parameter $\lambda$ is the horizontal distance from the midpoint of strip loading to the gravity center of failure wedge.

If the midpoint of strip load locates on the right of the action line of gravity center, the vertical distance $m$ from sites $D^{\prime}$ to $D$ can be expressed as

$$
m=\frac{\lambda B q}{(\cos \delta / \cos \alpha) E+\left(\cos [\Phi(T)] / \sin \theta_{\mathrm{cr}}\right) R \mu},
$$

where $\lambda=b+(B / 2)-d$. And the corresponding parameter $Z_{E_{a}}$ can be expressed as

$$
Z_{E_{a}}=\left(\frac{2}{3}\right) H+m .
$$

Meanwhile, if the midpoint of strip load is on the left of the action line of gravity center, the parameter $m$ can be listed as

$$
m=\frac{\lambda B q}{(\cos \delta / \cos \alpha) E+\left(\cos [\Phi(T)] / \sin \theta_{\mathrm{cr}}\right) R \mu_{1}},
$$

where $\lambda=d-b-(B / 2)$. Of course, $Z_{E_{a}}$ can be expressed as

$$
Z_{E_{a}}=\left(\frac{2}{3}\right) H-m .
$$

\section{Comparison and Discussions}

4.1. Extension Exploration of the Coulomb's Earth Pressure Based on the Equivalent Moment Model. A simplified analytical solution to solve the active thrust, wedge failure angle, and active thrust's action position is associated with the strip surcharge in the aforementioned section. As a matter of fact, it should be possible to obtain Coulomb's earth pressure parameters by means of our proposed equivalent moment model if any kinds of the local surcharge acting on the frozen backfill surface can satisfy the following two requirements simultaneously. Firstly, the local surcharge can be equivalent to one or more concentrated loadings. Secondly, the action positions of these equivalent concentrated loadings should be determined.

Extension explorations are also given in this section to discuss Coulomb's earth pressure evaluation under some other types of nonuniformly distributed surcharges such as double strip loading and triangular loading. The physical models and their corresponding equivalent moment models of double strip surcharge and triangular surcharge are demonstrated in Figures 4 and 5, respectively.

With respect to the double strip surcharges, it can also be simplified as the pattern that concentrated loadings and equivalent moments according to the similar equivalent moment model treatment. Therefore, the active thrust $E_{a}$ and its action position $Z_{E_{a}}$ can be expressed as follows.

The active thrust $E_{a}$ : 


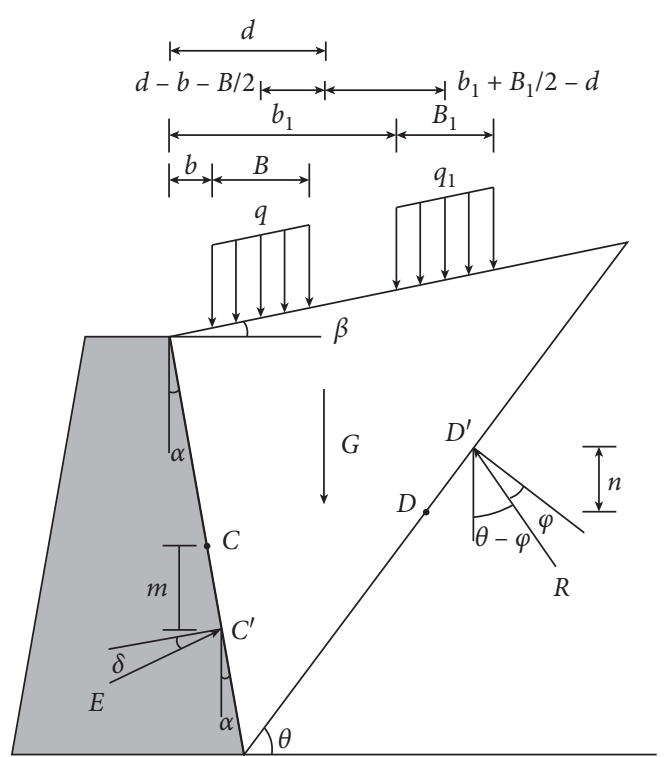

(a)

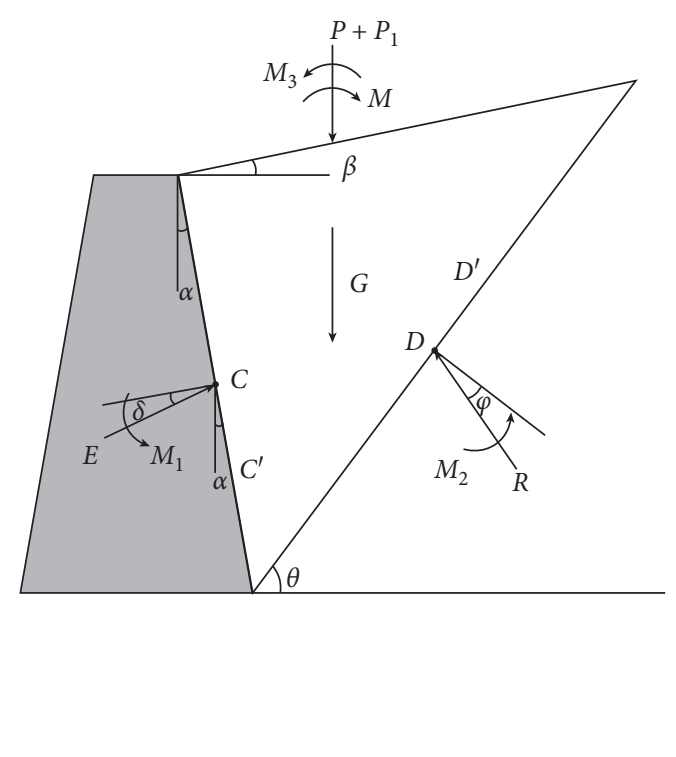

(b)

FIGURE 4: Double strip surcharge condition for the retaining wall. (a) Physical model. (b) Equivalent moment model.

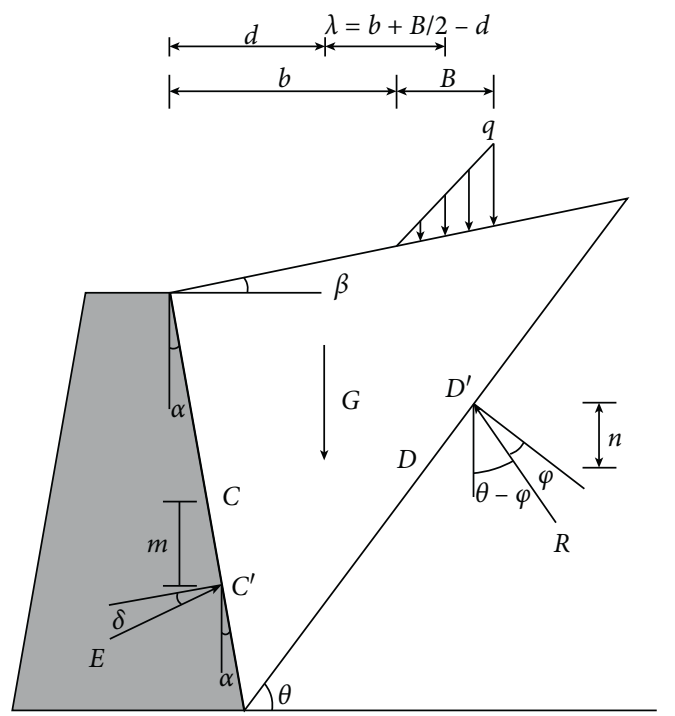

(a)

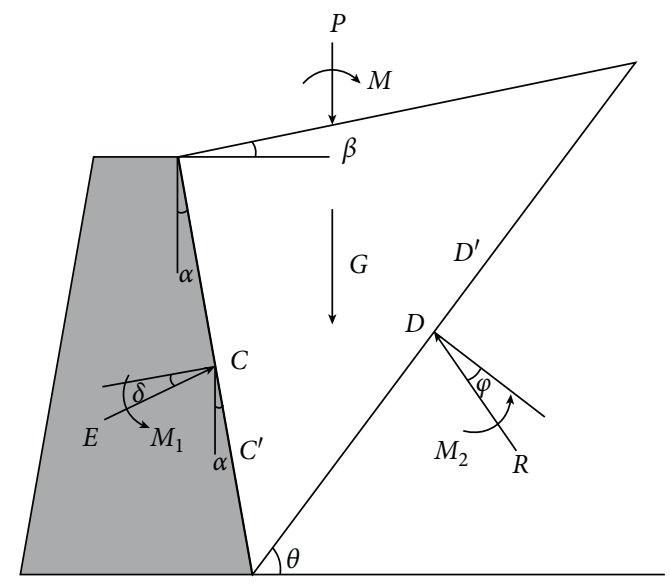

(b)

Figure 5: Continued. 


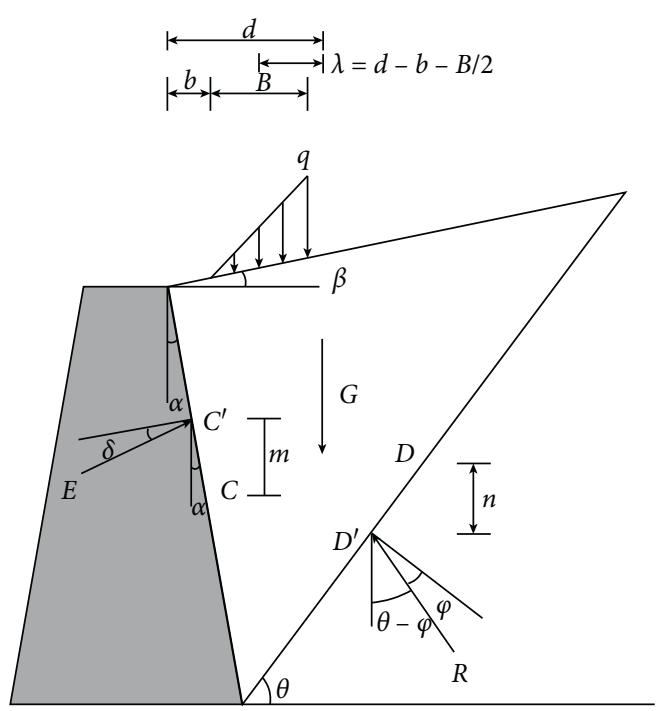

(c)

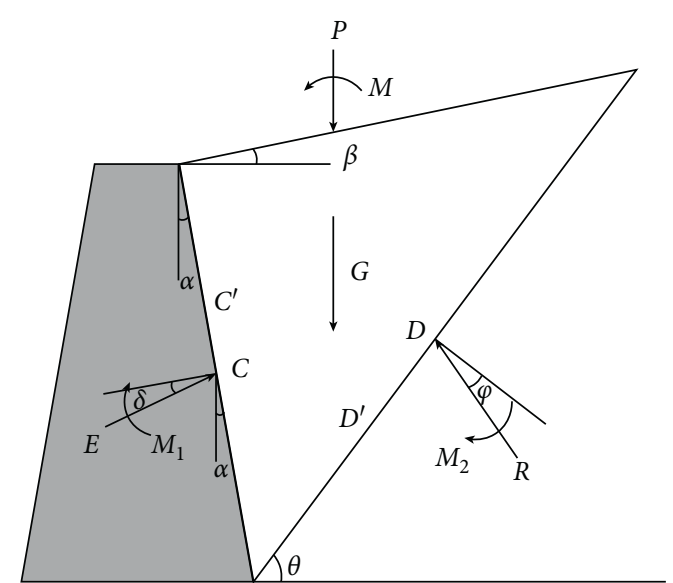

(d)

FIGURE 5: Triangular surcharge condition for the retaining wall. (a) Surcharge locates on the right of backfill gravity center; (b) corresponding equivalent moment model. (c) Surcharge locates on the left of backfill gravity center; (d) corresponding equivalent moment model.

$$
E_{a}=\frac{2\left(B q+B_{1} q_{1}\right) \cdot \cos ^{2} \alpha \cdot \sin \left(\theta_{\mathrm{cr}}-\beta\right)+\gamma H^{2} \cdot \cos (\beta-\alpha) \cdot \cos \left(\alpha-\theta_{\mathrm{cr}}\right)}{2 \cos ^{2} \alpha \cdot \sin (\alpha+\delta) \cdot \sin \left(\theta_{\mathrm{cr}}-\beta\right)+2 \cos ^{2} \alpha \cdot \cos (\alpha+\delta) \cdot \cot \left[\theta_{\mathrm{cr}}-\Phi(T)\right] \cdot \sin \left(\theta_{\mathrm{cr}}-\beta\right)} .
$$

If the total of equivalent moments $M+M_{3} \geq 0$, the active thrust's action position $Z_{E_{a}}$ should be expressed as

$$
Z_{E_{a}}=\left(\frac{2}{3}\right) H+m \text {. }
$$

where the parameter $m$ associated with vertical distance due to the surcharge should be represented as

$$
m=\frac{B_{1} q_{1}\left(b_{1}+\left(B_{1} / 2\right)-d\right)-B q(d-b-(B / 2))}{(\cos \delta / \cos \alpha) E_{a}+\left(\cos [\Phi(T)] / \sin \theta_{\mathrm{cr}}\right) R \mu} .
$$

If $M+M_{3} \leq 0$, the position $Z_{E_{a}}$ changes to another expression as

$$
Z_{E_{a}}=\left(\frac{2}{3}\right) H-m
$$

where the parameter $m$ is

$$
m=\frac{B q(d-b-(B / 2))-B_{1} q_{1}\left(b_{1}+\left(B_{1} / 2\right)-d\right)}{(\cos \delta / \cos \alpha) E_{a}+\left(\cos [\Phi(T)] / \sin \theta_{\mathrm{cr}}\right) R \mu_{1}} .
$$

Supposing that the surcharge working on the frozen backfill surface presents a triangular shape, it still can be simplified according to the proposed equivalent moment model. Meanwhile, the location of active force also can be divided into the left or right of the centroid of frozen backfill. The front physical model and its equivalent moment model are demonstrated in Figures 5(a) and 5(b), while the latter one is in Figures 5(c) and 5(d).

The active thrust $E_{a}$ has the same expression as follows regardless of the position of surcharge:

$$
E_{a}=\frac{B q \cdot \cos ^{2} \alpha \cdot \sin \left(\theta_{\mathrm{cr}}-\beta\right)+\gamma H^{2} \cdot \cos (\beta-\alpha) \cdot \cos \left(\alpha-\theta_{\mathrm{cr}}\right)}{2 \cos ^{2} \alpha \cdot \sin (\alpha+\delta) \cdot \sin \left(\theta_{\mathrm{cr}}-\beta\right)+2 \cos ^{2} \alpha \cdot \cos (\alpha+\delta) \cdot \cot \left[\theta_{\mathrm{cr}}-\Phi(T)\right] \cdot \sin \left(\theta_{\mathrm{cr}}-\beta\right)} .
$$

If the equivalent concentrated loading of triangular loading locates on the right of the action line of gravity center, the vertical distance $m$ from sites $D$, to $D$ can be expressed as

$$
m=\frac{\lambda B q}{(\cos \delta / \cos \alpha) 2 E_{a}+\left(\cos [\Phi(T)] / \sin \theta_{\mathrm{cr}}\right) 2 R \mu},
$$

where $\lambda=b+(2 B / 3)-d$. And the corresponding parameter $Z_{E_{a}}$ can be expressed as

$$
Z_{E_{a}}=\left(\frac{2}{3}\right) H+m
$$

If the equivalent concentrated loading of triangular loading is on the left of the action line of gravity center, the parameter $m$ can be listed as

$$
m=\frac{\lambda B q}{(\cos \delta / \cos \alpha) 2 E_{a}+\left(\cos [\Phi(T)] / \sin \theta_{c r}\right) 2 R \mu_{1}},
$$

where $\lambda=d-b-(2 B / 3)$. Of course, $Z_{E_{a}}$ can be expressed as 


$$
Z_{E_{a}}=\left(\frac{2}{3}\right) H-m
$$

4.2. Comparison with the Previous Models and the Current Proposed Model. Ke presented an analytical calculation to Coulomb's earth pressure on the basis of the closed vector polygon of force method [24]. The assumption of model is similar to the traditional Coulomb's earth pressure theory, but the strip surcharge was taken into account and the cohesive force of backfill was not ignored. His analytical solution to Coulomb's earth pressure could be acquired with the help of complicated iterative computation. It is hard to use into practice unless undergoing a computer calculation program. Moreover, the action position of active thrust cannot be achieved for this method. Ying proposed a static equilibrium model to analyze the effect of strip loading on the active earth pressure for cohesion-less backfill [41]. The model is relatively simple and easier to apply into the calculation of Coulomb's earth pressure. However, a significant drawback exists that the effect of surcharge on the critical wedge failure angle $\theta_{\text {cr }}$ has been ignored. In fact, the critical wedge failure angle should be changed remarkably if the extra surcharge appears. Furthermore, the back face of retaining wall was limited as the vertical condition (that is, $\alpha=0$ ) and the action position of active thrust was also not obtained in virtue of this method. Greco developed a meaningful analytical solution to analyze the effect of strip surcharge on active earth pressure for cohesion-less backfill [43]. He adopted the sectional static equilibrium method to study the influence of strip surcharge locating on different given positions on the Coulomb's earth pressure. The backfill was divided into some subblocks in the light of the active positions of surcharges and the toe of retaining wall. This method should be more comprehensive to calculate all the involved parameters relative to active Coulomb's earth pressure than the above two methods. However, it still has some defects that the calculation process is too complicated to extend into practical engineering and nonuniformly distributed loading cannot be worked.

In addition, the physical and mechanical parameters of frozen backfill are deeply affected by soil temperature [34-37, 44, 48, 49]. For cohesion-less frozen backfill, soil has different internal friction angles under variable temperature conditions. According to the results of experimental study carried out by Yan et al. [44], the variation of internal friction angle of soil with temperature during freezing and thawing process is shown in Figure 6. With the decrease of soil temperature, the internal friction angles of frozen soil obviously decrease, and there are three changing stages. Under positive temperature, the internal friction angle has little change. When water-ice phase transition begins, the internal friction angle gradually decreases. In the stable freezing stage, the internal friction angle slowly decreases. In addition, the internal friction angle in frozen period is slightly higher than that in thawed period. Yan et al. believed that it is caused by the pressure melting action of frozen soil. Therefore, with the decrease of frozen soil temperature, the

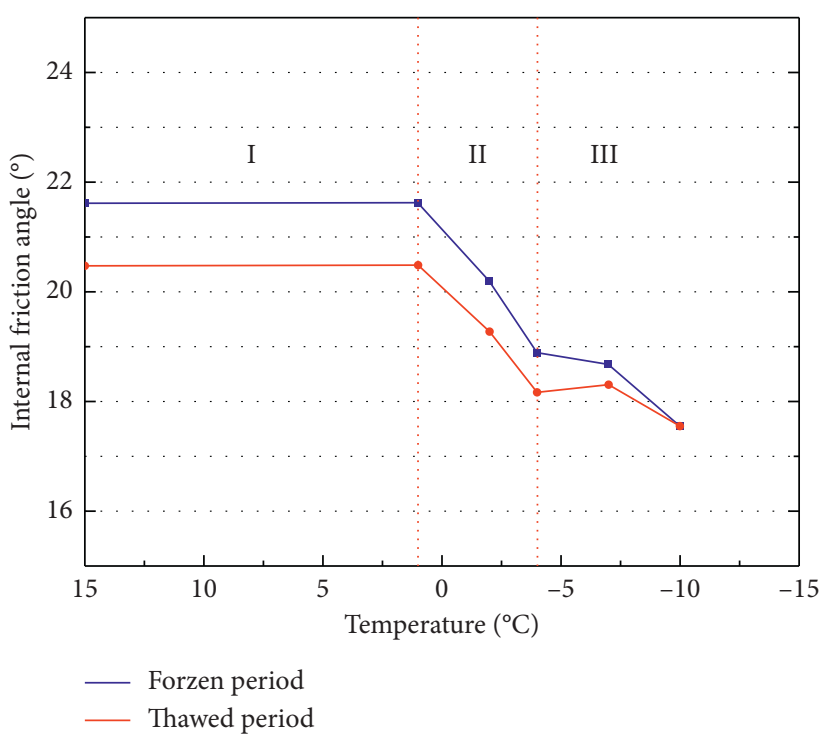

Figure 6: Variation of internal friction angle of soil with temperature during freezing and thawing process [44].

TABLE 1: Basic parameters of a cohesive-less backfill retaining wall.

\begin{tabular}{lcccc}
\hline $\mathrm{H}(\mathrm{m})$ & $\mathrm{c}(\mathrm{kPa})$ & $\varphi\left({ }^{\circ}\right)$ & $\gamma\left(\mathrm{kN} \cdot \mathrm{m}^{-3}\right)$ & $\delta\left({ }^{\circ}\right)$ \\
\hline 4.6 & 0 & 15 & 19.3 & 10 \\
\hline
\end{tabular}

active thrust, critical wedge failure angle, and action position subjected to various surcharge will vary, which can be calculated by the above equations.

In order to verify the accuracy of new equivalent moment model, a cohesive-less frozen backfill retaining wall suffering from different strip surcharges is chosen as a typical case to compare with the aforementioned other models [24, 41, 43]. The detailed basic parameters are listed in Table 1 . The involved parameters $E_{a}, \theta_{\mathrm{cr}}$, and $Z_{E_{a}}$ with the Coulomb's active earth pressure would tend to change along with changes of these variables $\alpha, \beta, b, B$, and $q$. We used the mathematical calculation program Matlab 7.0 [47]. Table 2 presents a comprehensive calculation list aiming at the previous works $[24,41,43]$ and our proposed model.

According to the comparison results among these models, it is clear that the results using the new equivalent moment model are close to other methods. It can be verified that our proposed model should be reliable to analyze Coulomb's active earth pressure subject to the local surcharge. Moreover, it can be observed that there are more advantages. Firstly, the calculation results using this model are more comprehensive than other methods; all the involved parameters $\left(E_{a}, \theta_{c r}\right.$, and $\left.Z_{E_{a}}\right)$ can be obtained simultaneously by the equivalent moment model. However, it is difficult to achieve all the results by the other methods. Secondly, this model includes more kinds of local surcharge conditions; it provides a new way to calculate the active earth pressure aiming at any kinds of local surcharges. Thirdly, the mechanics concept of this model is definite and the calculation formula as well as the analysis process is relatively 
TABLE 2: Comparison of Coulomb's active earth pressure results between previous studies and our work.

\begin{tabular}{|c|c|c|c|c|c|c|c|c|c|c|c|c|c|}
\hline \multirow[b]{2}{*}{$\alpha\left({ }^{\circ}\right)$} & \multirow[b]{2}{*}{$\beta\left(^{\circ}\right)$} & \multirow[b]{2}{*}{$b(\mathrm{~m})$} & \multirow[b]{2}{*}{$B(\mathrm{~m})$} & \multirow[b]{2}{*}{$q(\mathrm{kPa})$} & \multicolumn{5}{|c|}{$E_{a}\left(\mathrm{kN} \cdot \mathrm{m}^{-3}\right)$} & \multicolumn{2}{|l|}{$\theta_{\mathrm{cr}}\left({ }^{\circ}\right)$} & \multicolumn{2}{|c|}{$Z_{E_{a}}(\mathrm{~m})$} \\
\hline & & & & & $\begin{array}{c}\text { Equations (10) } \\
\text { and (11) }\end{array}$ & $\operatorname{Ke}[7]$ & $\begin{array}{l}\text { Ying } \\
\text { [41] }\end{array}$ & $\begin{array}{c}\text { Greco } \\
{[43]}\end{array}$ & Coulomb & $\begin{array}{l}\text { Equations (10) } \\
\text { and (11) }\end{array}$ & $\begin{array}{c}\mathrm{Ke} \\
{[24]}\end{array}$ & $\begin{array}{l}\text { Equation } \\
(14)\end{array}$ & $\begin{array}{c}\text { Greco } \\
{[43]}\end{array}$ \\
\hline 0 & 0 & 0 & 0 & 0 & 108.86 & 108.90 & 108.90 & 108.90 & 108.90 & 47.011 & 47.008 & 3.067 & 2.831 \\
\hline 0 & 0 & 1 & 2 & 10 & 121.26 & 121.30 & 117.20 & 124.13 & - $^{*}$ & 52.172 & 52.167 & 3.017 & 2.764 \\
\hline 10 & 0 & 1 & 2 & 10 & 136.14 & 136.20 & - & 137.65 & - & 56.061 & 56.053 & 3.113 & 2.924 \\
\hline 0 & 10 & 1 & 2 & 10 & 143.55 & 146.60 & 137.32 & 157.28 & - & 39.964 & 56.920 & 3.029 & 2.641 \\
\hline 10 & 10 & 1 & 2 & 10 & 163.28 & 162.30 & - & 171.10 & - & 41.471 & 41.458 & 3.034 & 2.811 \\
\hline
\end{tabular}

simple. It should be regarded as more widely applied in engineering practice.

\section{Sensitive Analysis of Important Influence Indexes on Active Earth Pressure}

In practical engineering, it is very important to reduce the lateral earth pressure against the retaining structure and maintain the retaining structure stable. Therefore, it is worthy assessing the effect of various parameters on the Coulomb's active earth pressure. The influences of $\alpha$ (dip angle of the retaining wall-back), $\beta$ (dip angle of the frozen backfill soil), $\delta$ (friction angle of the retaining wall-back), and $\varphi$ (friction angle of the frozen backfill soil) are illustrated below using sensitivity analyses. The value of one parameter is varied while those of others are kept constant to assess their effect on the Coulomb's active earth pressure parameters $E_{a}, \theta_{\mathrm{cr}}$, and $Z_{E_{a}}$. The value intervals have been listed in Table 3.

Figure 7 presents the influence characteristics of these variables on changes of active thrust $E_{a}$ along with the increase of concentrated loading $P$. Some significant phenomenon can be summarized: (1) the active thrust $E_{a}$ tends to a linear increase following the surcharge increasing, which is suitable to the actual practice. (2) For the friction angles of failure wedge, the active thrust $E_{a}$ commonly decreases accompanied with the variables $\delta$ and $\varphi$ increasing; meanwhile, the friction angle of frozen backfill soil $\varphi$ has much more significant influence on the active earth pressure than the friction angle of retaining wall-back $\delta$. In cold regions, it is more meaningful for improving the roughness of wall-back to fill with more coarse backfill and pay attention to changes in ambient temperature during the actual practice. (3) While for these geometric parameters of failure wedge, the active thrust $E_{a}$ presents an increase trend along with the increase of $\alpha$ and $\beta$. Particular, the sensitivity of dip angle of retaining wall-back $\alpha$ on the active thrust $E_{a}$ was much greater than that of the dip angle of frozen backfill soil $\beta$, which implies a fact that the selection of vertical wall-back should be more effective than reducing the frozen backfill dip angle if the aim is to reduce the active earth pressure.

Figure 8 presents the influence characteristics of these variables on changes of critical wedge failure angle $\theta_{\mathrm{cr}}$ along with the increase of concentrated loading $P$. It has some similar change rules as the active thrust $E_{a}$ with the variables changing. For instance, it also tends to a linear increase with the surcharge increasing and has a positive relationship with
TABLE 3: Basic value and the corresponding contrast values of these variables.

\begin{tabular}{lcccc}
\hline Variable & $\alpha\left(^{\circ}\right)$ & $\beta\left(^{\circ}\right)$ & $\delta\left({ }^{\circ}\right)$ & $\varphi\left({ }^{\circ}\right)$ \\
\hline Basic value & 36 & 24 & 10 & 15 \\
Contrast value & 30 & 18 & 5 & 10 \\
\hline
\end{tabular}

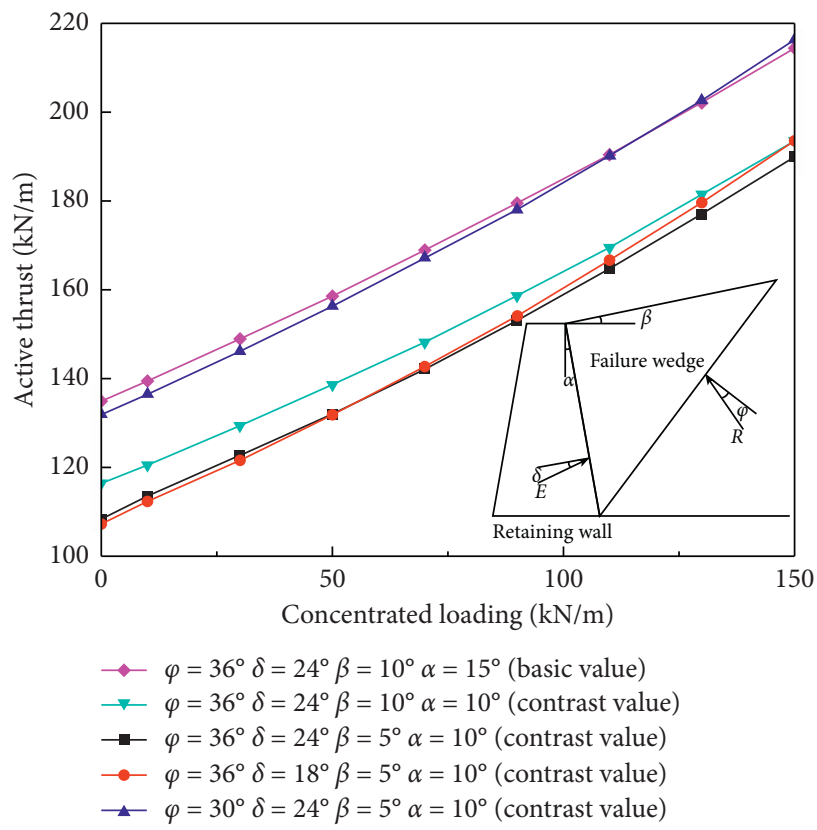

Figure 7: Variations of the active thrust $E_{a}$ with the involved variables.

the dip angle of retaining wall-back $\alpha$ and the friction angle of frozen backfill soil $\varphi$. Specifically, the critical wedge failure angle $\theta_{\text {cr }}$ has a contrast trend with the change of dip angle of frozen backfill soil $\beta$ and the friction angle of retaining wallback $\delta$. Furthermore, the sensitivity of dip angle of retaining wall-back $\alpha$ has an approximate influence on the parameter $\theta_{\text {cr }}$ with the index $\beta$, which is much different from its impact on the active thrust $E_{a}$. Meanwhile the friction angle of frozen backfill soil $\varphi$ has much more significant influence on the critical wedge failure angle than the index $\delta$.

Figure 9 displays the change characteristics of the action position $Z_{E_{a}}$ of active thrust with the distance $b$ between surcharge position and wall-back. It should be emphasized that the index $\mu$ has a little impact on the action position $Z_{E_{a}}$ 


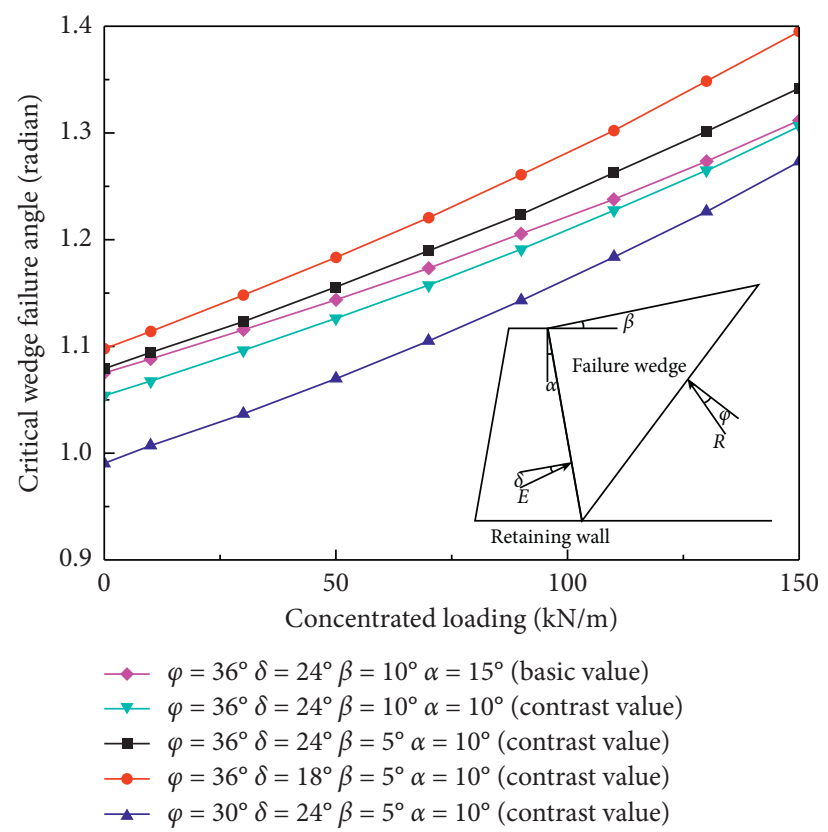

Figure 8: Variations of the critical wedge failure angle $\theta_{\text {cr }}$ with the involved variables.

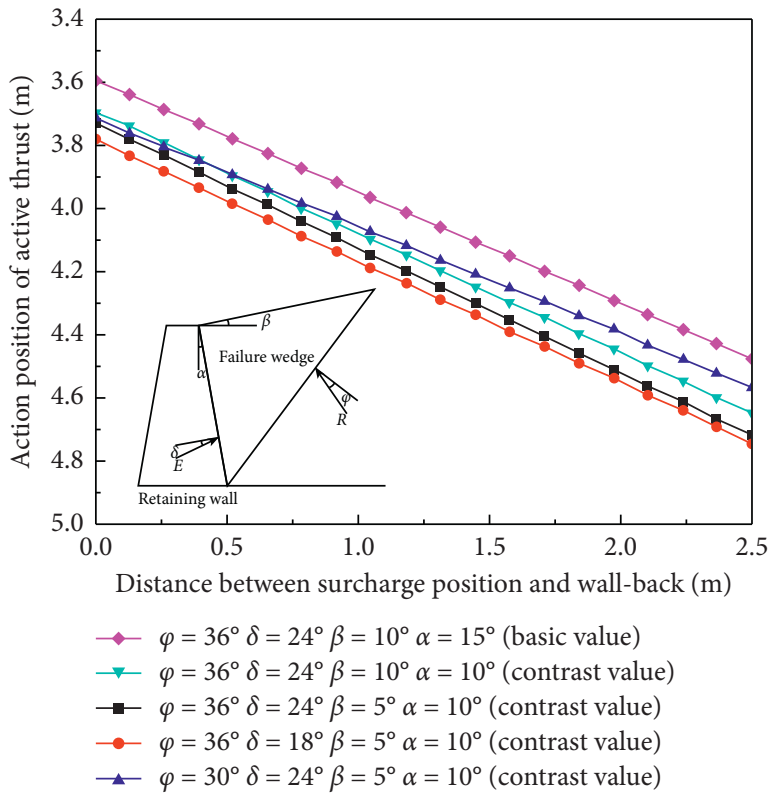

(a)

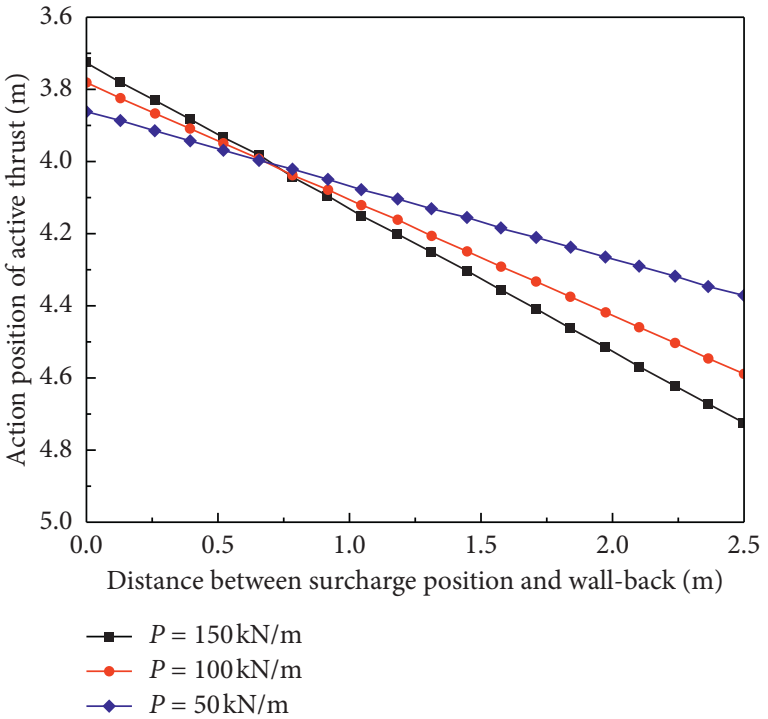

(b)

Figure 9: Variation of the active position $Z_{E_{\alpha}}$ of active thrust with the distance $b$. (a) Referring to the parameters $\varphi, \delta$, $\beta$, and $\alpha$; (b) referring to the concentrated surcharge.

of active thrust. However, it is much less important to change the failure wedge characteristics compared with frozen backfill materials and wall-back roughness, so it is simplified as a constant $\mu=1$.

According to Figure 9(a), the action position $Z_{E_{a}}$ tends to a linear decline along with the distance $b$, which means the active thrust changes to be deeper with the surcharge far away from the wall-back. Meanwhile, it is also clear that the action position $Z_{E}$ has a rising trend to the surface along with the increase of $\alpha$ and $\beta$. And it also tends to the shallow condition together with the increase of $\delta$ and the decrease of $\varphi$. The higher sensitivity of these parameters on the action position $Z_{E_{a}}$ is still the indexes $\alpha$ and $\varphi$.

\section{Conclusion}

In this work, an analytical solution of active thrust, critical wedge failure angle, and its action position under the effect of local surcharge in cold regions is presented. This method can be considered the effect of any kind of local surcharge 
and freeze-thaw environment comprehensively. Some main conclusions can be listed as follows.

(1) A simplified equivalent moment model of surcharge is proposed in this work on the premise of maintaining the basic Coulomb's earth pressure assumptions. The detailed derivation procedures are provided as a typical example to obtain the active thrust, critical wedge failure angle, and its action position subject to a strip surcharge. Compared with the previous approaches, it tends to be easier to evaluate all parameters $\left(E_{a}, \theta_{\mathrm{cr}}\right.$, and $\left.Z_{E_{a}}\right)$ of the Coulomb's active earth pressure than those previous studies.

(2) Any kinds of the local surcharge even nonuniformly distributed loading acting on the frozen backfill surface can satisfy the following two requirements simultaneously. Our proposed equivalent moment model can be suitable to calculate Coulomb's earth pressure parameters. Firstly, the local surcharge can be equivalent to one or more concentrated loadings. Secondly, the action positions of these equivalent concentrated loadings are clear.

(3) After comparing the previous models with the proposed equivalent moment model, it has been verified that our proposed model is reliable to analyze Coulomb's active earth pressure subject to the local surcharge in cold regions. Moreover, it has more advances that the calculation results are more comprehensive and contain more kinds of local surcharges. Furthermore, the mechanics concept of this model is definite and the calculation formula as well as analysis process is relatively simple.

(4) The sensitivities of some main variables $(\alpha, \beta, \delta$, and $\varphi)$ involving the Coulomb's earth pressure are also analyzed, and we found that the dip angle $\alpha$ of the retaining wall-back and the friction angle $\varphi$ of the frozen backfill soil are two most significant indexes that influence the active thrust and its action position. Particular, the internal friction angle $\varphi$ of frozen backfill soil gradually decreases at negative temperature.

\section{Notations}

q: The intensity of local loading

$B$ : The width of local loading

$b$ : The distance between surcharge position and wall-back

G: The total weight of cohesive-less soil wedge

$E$ : The resultant back force

$E^{\prime}$ : The resultant back force (considering the total weight of soil wedge only)

$E_{a}$ : Active thrust

$R: \quad$ The resultant counter force

$R^{\prime}$ : The resultant counter force (considering the total weight of soil wedge only)

$C^{\prime}$ : The action site of $E$

$C: \quad$ The action site of $E^{\prime}$
$D^{\prime}$ : The action site of $R$

$D$ : The action site of $R^{\prime}$

$Z_{E_{a}}$ : Active thrust $E_{a}$ 's action position

$P: \quad$ The equivalent concentrated loading of local loading

$M$ : Equivalent additional moment associated with $P$

$M_{1}$ : Equivalent additional moment associated with $E$

$M_{2}$ : Equivalent additional moment associated with $R$

$n$ : Vertical distance from $C^{\prime}$ to $C$

$m$ : Vertical distance from $D^{\prime}$ to $D$

$\mu$ : $\quad$ Ratio between vertical distance from $C^{\prime}$ to $C$ and vertical distance from $D^{\prime}$ to $D$

$H$ : Height of retaining wall

$\theta$ : Wedge failure angle

$\theta_{\text {cr }}:$ Critical value of $\theta$

$a$ : The dip angle of the retaining wall-back

$\beta: \quad$ The dip angle of the backfill soil

$\delta$ : Wall friction angle

$\varphi$ : The friction angle of the backfill soil

$\gamma$ : Unit weight of soil

$d$ : The horizontal distance from the centroid (center of gravity) of failure wedge to the vertex of wall-back

$\lambda$ : The horizontal distance from the equivalent concentrated loading to the gravity center of failure wedge

$\eta$ : Angle between the midline of probable failure wedge and the back face of wall

$J$ : The length of probable failure surface

$e$ : The distance from the midpoint of probable failure surface to the vertex of back face of wall

$L$ : The length of the upper face of probable failure wedge

$S$ : The area of probable failure wedge.

\section{Data Availability}

All data, models, and code generated or used during the study appear in the submitted article.

\section{Conflicts of Interest}

The authors declare no conflicts of interest.

\section{Acknowledgments}

This work was supported by the National Natural Science Foundation of China (grant no. 41302228) and Key Scientific and Technological Innovation Team Foundation of Shaanxi (grant nos. 2014KCT-30).

\section{References}

[1] C. A. Coulomb, "An attempt to apply the rules of maxima and minima to several problems of stability related to architecture," Mémoires de l'Académie Royale des Sciences, vol. 7, pp. 343-382, 1776.

[2] Y. Zheng, P. J. Fox, and J. S. McCartney, "Numerical simulation of deformation and failure behavior of geosynthetic reinforced soil bridge abutments," Journal of Geotechnical and Geoenvironmental Engineering, vol. 144, no. 7, 2018.

[3] P. Rao, Q. Chen, Y. Zhou, S. Nimbalkar, and G. Chiaro, "Determination of active earth pressure on rigid retaining wall 
considering arching effect in cohesive backfill soil," International Journal of Geomechanics, vol. 16, no. 3, 2016.

[4] M. Jesmani, H. Alirezanejad, H. F. Kashani, and M. Kamalzare, "Numerical study of the dynamic active lateral earth pressure coefficient of cohesive soils," Acta Geotechnica Slovenica, vol. 14, no. 1, pp. 75-87, 2017.

[5] Y. Cai, Q. Chen, Y. Zhou, S. Nimbalkar, and J. Yu, "Estimation of passive earth pressure against rigid retaining wall considering arching effect in cohesive-frictional backfill under translation mode," International Journal of Geomechanics, vol. 17, no. 4, 2017.

[6] F. Chen, J. Yang, and Y. Lin, "Active Earth pressure of narrow granular backfill against rigid retaining wall near rock face under translation mode," International Journal of Geomechanics, vol. 19, no. 12, 2019.

[7] C. T. Ke, Y. B. Chen, H. B. Gao, and X. Cao, "Active earth pressure on retaining wall under different distribution patters of strip surcharge," Chinese Journal of Geotechnical Engineering, vol. 35, no. 10, pp. 1922-1927, 2013.

[8] J. Peng, Y. Zhu, and Y. Zhou, "Derivation of Shukla's generalized expression of seismic passive earth pressure on retaining walls with cohesive-frictional backfill by the inclined slice element method," Soil Dynamics and Earthquake Engineering, vol. 114, pp. 225-228, 2018.

[9] D.-F. Zheng, T.-K. Nian, B. Liu, P. Yin, and L. Song, "Coefficient charts for active earth pressures under combined loadings," Geomechanics and Engineering, vol. 8, no. 3, pp. 461-476, 2015.

[10] J. Maciejewski and A. Jarzbowski, "Application of kinematically admissible solutions to passive earth pressure problems," International Journal of Geomechanics, vol. 4, no. 2, pp. 127-136, 2004.

[11] K. S. Subba Rao and D. Choudhury, "Seismic passive earth pressures in soils," Journal of Geotechnical and Geoenvironmental Engineering, vol. 131, no. 1, pp. 131-135, 2005.

[12] R. T. Cole and K. M. Rollins, "Passive earth pressure mobilization during cyclic loading," Journal of Geotechnical and Geoenvironmental Engineering, vol. 132, no. 9, pp. 1154-1164, 2006.

[13] F. Jacobs, A. Ruiken, and M. Ziegler, "Investigation of kinematic behavior and earth pressure development of geogrid reinforced soil walls," Transportation Geotechnics, vol. 8, pp. 57-68, 2016.

[14] M. Ernesto, "Generalized Coulomb active earth pressure for distanced surcharge," Journal of Geotechnical Engineering, vol. 120, no. 6, pp. 1072-1079, 1994.

[15] Z. H. Mazindranj and M. H. Ganjal, "Lateral earth pressure problem of cohesive backfill with inclined surface," Journal of Geotechnical and Geoenvironmental Engineering, vol. 123, no. 2, pp. 110-112, 1997.

[16] N. Gnanapragasam, "Active earth pressure in cohesive soils with an inclined ground surface," Canadian Geotechnical Journal, vol. 37, no. 1, pp. 171-177, 2000.

[17] J. Kumar and S. Chitikela, "Seismic passive earth pressure coefficients using the method of characteristics," Canadian Geotechnical Journal, vol. 39, no. 2, pp. 463-471, 2002.

[18] J. W. Li, C. Wang, and Y. D. Liang, "Computation of earth pressure of cohesive backfill on retaining wall," Chinese Journal of Geotechnical Engineering, vol. 28, no. 8, pp. 650652, 2006.

[19] N. Reddy, D. M. Dewaikar, and G. Mohapatro, "Computation of passive pressure coefficients: for a horizontal cohesionless backfill with surcharge using method of slices," International Journal of Geomechanics, vol. 8, no. 4, pp. 463-468, 2014.
[20] Y. S. Fang, T. J. Chen, and B. F. Wu, "Passive earth pressures with various wall movements," Journal of Geotechnical Engineering, vol. 120, no. 8, pp. 1307-1323, 1994.

[21] M. Sabermahani, A. Ghalandarzadeh, and A. Fakher, "Experimental study on seismic deformation modes of reinforced-soil walls," Geotextiles and Geomembranes, vol. 27, pp. 121-136, 2009.

[22] M. A. Patki, D. M. Dewaikar, and J. N. Mandal, "Numerical evaluation of passive earth-pressure coefficients under the effect of surcharge loading," International Journal of Geomechanics, vol. 17, no. 3, 2017.

[23] S. Nama, A. K. Saha, and S. Ghosh, "Improved backtracking search algorithm for pseudo dynamic active earth pressure on retaining wall supporting c- $\Phi$ backfill," Applied Soft Computing, vol. 52, pp. 885-897, 2017.

[24] C. T. Ke, Y. B. Chen, H. B. Gao, and H. B. Xie, "Calculation of active earth pressure for cohesive soil under action of strip surcharge," Chinese Rock and Soil Mechanics, vol. 34, no. 1, pp. 167-172, 2013.

[25] O. Farzaneh, F. Askari, and J. Fatemi, "Active earth pressure include by strip loads on a backfill," International Journal of Civil Engineering, vol. 12, no. 4, pp. 281-291, 2014.

[26] M. Georgiads and C. Anagnostopoulos, "Lateral pressure on sheet pile walls due to strip load," Journal of Geotechnical and Geoenvironmental Engineering, vol. 124, no. 1, pp. 95-98, 1998.

[27] Y. Zhao, "Numerical analysis and model test of earth pressure on rigid retaining wall in high-speed railway," Chinese Southwest Jiaotong University, Master Degree Thesis, 2006.

[28] J. Wang, K. Jia, R. Rafique et al., "Changes of backfill soil of tower foundation in the permafrost regions with warm icerich frozen soil on the Qinghai-Tibet Plateau," Environmental Earth Sciences, vol. 75, no. 21, 2016.

[29] Y. Shen, H. Yang, J. Xi, Y. Yang, Y. Wang, and X. Wei, “A novel shearing fracture morphology method to assess the influence of freeze-thaw actions on concrete-granite interface," Cold Regions Science and Technology, vol. 169, 2020.

[30] Y. Shen, H. Yang, L. Jin, H. Zhang, G. Yang, and J. Zhang, "Fatigue deformation and energy change of single-joint sandstone after freeze-thaw cycles and cyclic loadings," Frontiers in Earth Science, vol. 7, 2019.

[31] H. Lin, H. Wang, X. Fan, P. Cao, and K. Zhou, "Particle size distribution effects on deformation properties of graded aggregate base under cyclic loading," European Journal of Environmental and Civil Engineering, vol. 23, no. 3, pp. 269-286, 2019.

[32] Y. You, Q. Yu, L. Guo et al., "In-situ monitoring the thermal regime of foundation backfill of a power transmission line tower in permafrost regions on the Qinghai-Tibet Plateau," Applied Thermal Engineering, vol. 98, pp. 271-279, 2016.

[33] L. Guo, Z. Zhang, X. Wang et al., "Stability analysis of transmission tower foundations in permafrost equipped with thermosiphons and vegetation cover on the Qinghai-Tibet Plateau," International Journal of Heat and Mass Transfer, vol. 121, pp. 367-376, 2018.

[34] D. Zhang, E. Liu, X. Liu, G. Zhang, and B. Song, "A new strength criterion for frozen soils considering the influence of temperature and coarse-grained contents," Cold Regions Science and Technology, vol. 143, pp. 1-12, 2017.

[35] J. Teng, J. Kou, X. Yan, S. Zhang, and D. Sheng, "Parameterization of soil freezing characteristic curve for unsaturated soils," Cold Regions Science and Technology, vol. 170, Article ID 102928, 2020. 
[36] X. Liu, E. Liu, D. Zhang, G. Zhang, and B. Song, "Study on strength criterion for frozen soil," Cold Regions Science and Technology, vol. 161, pp. 1-20, 2019.

[37] J. Xu, H. Liu, and X. Zhao, "Study on the strength and deformation property of frozen silty sand with $\mathrm{NaCl}$ under triaxial compression condition," Cold Regions Science and Technology, vol. 137, pp. 7-16, 2017.

[38] K. Terzaghi, Theoretical Soil Mechanics, John Wiley and Sons, New York, NY, USA, 1943.

[39] R. L. Handy, "The arch in soil arching," Journal of Geotechnical Engineering, vol. 111, no. 3, pp. 302-318, 1985.

[40] K. H. Paik and R. Salgado, "Estimation of active earth pressure against rigid retaining walls considering arching effects," Géotechnique, vol. 53, no. 7, pp. 643-653, 2003.

[41] H. W. Ying, B. Jiang, and K. H. Xie, "Active earth pressure on retaining wall due to strip surcharge," Chinese Rock and Soil Mechanics, vol. 28, no. 4, pp. 183-186, 2007.

[42] V. R. Greco, "Active earth thrust on cantilever walls in general conditions," Soils and Foundations, vol. 39, no. 6, pp. 65-78, 1999.

[43] V. R. Greco, "Lateral earth pressure due to backfill subject to a strip of surcharge," Geotechnical and Geological Engineering, vol. 24, no. 3, pp. 615-636, 2006.

[44] C. Yan, T. Wang, H. Jia et al., "Influence of the unfrozen water content on the shear strength of unsaturated silt during freezing and thawing," Chinese Journal of Rock Mechanics and Engineering, vol. 38, no. 6, pp. 1252-1260, 2019, in Chinese.

[45] M. Ahmadabadi and N. Bahraminezhad, "Active earth pressure of modeled strip load surcharge on rigid walls," National Congress on Civil Engineering, vol. 6, no. 8, pp. 3-7, 2011.

[46] M. Ahmadabadi and M. K. Faghirizadeh, "Design diagrams for the analysis of active pressure on retaining walls with the effect of line surcharge," Advances in Civil Engineering, vol. 2017, Article ID 9897658, 9 pages, 2017.

[47] J. Lofberg, "YALMIP: a toolbox for modeling and optimization in MATLAB," in Proceedings of the 2004 IEEE International symposium on Computer Aided Control Systems Design, pp. 284-289, Taipei, Taiwan, September 2004.

[48] S. Li, M. Zhang, W. Pei, and Y. Lai, "Experimental and numerical simulations on heat-water-mechanics interaction mechanism in a freezing soil," Applied Thermal Engineering, vol. 132, pp. 209-220, 2018.

[49] J. Xu, S. Wang, Z. Wang, L. Jin, and J. Yuan, "Heat transfer and water migration in loess slopes during freeze-thaw cycling in Northern Shaanxi, China," International Journal of Civil Engineering, vol. 16, no. 11, pp. 1591-1605, 2018. 